\title{
Studi Penentuan Status Mutu Dan Kualitas Air Sungai Klawili Km.12 Kota Sorong
}

\author{
Sri Rahayu ${ }^{1}$, Hendrik Pristianto ${ }^{2}$ \\ 1,2 Program Studi Teknik Sipil Universitas Muhammadiyah Sorong
}

\begin{abstract}
Abstrak
Penambahan tingkat pencemaran Sungai Klawili diakibatkan oleh pembuangan sampah dan limbah yang langsung ke badan sungai. Dengan demikian maka dilakukan peninjauan kualitas air sungai untuk mengetahui status mutu, pengaruh tata ruang bantaran Sungai Klawili dan rekomendasi pengendalian pencemaran air. Penelitian ini dilakukan berdasarkan beberapa sifat fisika dan kimia sesuai dengan PP No 82 Tahun 2001 dengan penentuan status mutu menggunakan Metode Indeks Pencemaran dan pemetaan menggunakan software ArcGis 10.3. Hasil penelitian ini menunjukkan bahwa status mutu air Sungai Klawili di titik pantau 1 (hulu) masuk dalam kategori cemar ringan untuk baku mutu kelas I dengan nilai IP 1,70 dan status memenuhi untuk baku mutu kelas II-IV dengan nilai IP 0,73. Pada titik pantau 2 (tengah) masuk dalam kategori cemar ringan untuk baku mutu kelas I dengan nilai IP 3,71 dan status memenuhi untuk baku mutu kelas II-IV dengan nilai IP 0,60. Kemudian pada titik pantau 3 (hilir) masuk dalam kategori cemar ringan untuk baku mutu kelas I dengan nilai IP 3,77 dan status memenuhi untuk baku mutu kelas II-IV dengan nilai IP 0,54 berdasarkan Peraturan Pemerintah Nomor 82 Tahun 2001. Untuk pengaruh tata ruang bantaran sungai dengan menggunakan observasi dan pemetaan diperoleh pengaruh pencemaran air Sungai Klawili adalah limbah rumah tangga dan sampah organik maupun anorganik, kemudian rekomendasi pengendalian pencemaran air tersebut diperlukan pembuatan septictank karena adanya limbah cair rumah tangga yang langsung dialirkan ke sungai serta perlu adanya pembuatan bak sampah pada beberapa tempat disepanjang Sungai Klawili dan sirkulasi pengambilan sampah yang berkala.
\end{abstract}

Kata kunci : Baku Mutu, Kualitas Air, Metode Indeks Pencemaran mutu, Status Mutu Air.

\section{Pendahuluan}

\subsection{Latar Belakang}

Sungai memiliki sifat dinamis, maka dalam pemanfaatan potensinya dapat mengurangi nilai manfaat sungai dan membahayakan lingkungan secara luas. Pencemaran akibat pembuangan limbah cair domestik, pertanian dan industri menyebabkan turunnya kualitas air sungai. Sebagai contoh turunnya daya dukung sungai dimana badan air sungai sering digunakan sebagai media akhir pembuangan limbah dari segala kegiatan manusia. Demikian juga yang terjadi pada Sungai Klawili kota Sorong dimana dengan bertambahnya jumlah kegiatan atau industri kecil serta berkembangnya hasil produksi di sungai tersebut, maka tentunya akan beresiko terhadap turunnya daya dukung sungai dan hilangnya estika pada sungai tersebut.

Berdasarkan hasil penelitian Pristianto (2017), disebutkan bahwa kualitas air Sungai Klawili memiliki temperature $=29.10{ }^{\circ} \mathrm{C}$, kadar $\mathrm{pH}=6.60$, $\mathrm{DO}=2.54 \mathrm{mg} / \mathrm{l}$, dan TDS $=73.00 \mathrm{mg} / \mathrm{l}$. Dari hasil penelitian tersebut yang menjadi perhatian adalah kadar DO pada Sungai Klawili sangatlah rendah. Rendahnya kadar DO pada air mengindikasikan bahwa kondisi sungai telah tercemar, sehingga kualitas air Sungai Klawili tidak layak untuk kehidupan flora dan fauna.

Mengacu pada kondisi tersebut diperlukan upaya pemantauan lebih lanjut terhadap kondisi Sungai Klawili. Upaya pemantauan dilakukan untuk memberi informasi faktual tentang kondisi kualitas air masa sekarang.

\subsection{Tujuan Penelitian}

Penelitian ini bertujuan untuk : (1) Menganalisa status mutu air Sungai Klawili berdasarkan Peraturan Pemerintah Nomor 82 Tahun 2001 tentang pengelolaan kualitas air dan pengendalian pencemaran air. (2) Mengkaji pengaruh tata ruang bantaran Sungai Klawili terhadap status mutu air. (3) Mengidentifikasi pengendalian pencemaran air pada Sungai Klawili.

\section{Metode}

Metode penelitian yang dilakukan dapat dilihat pada Gambar 1. 


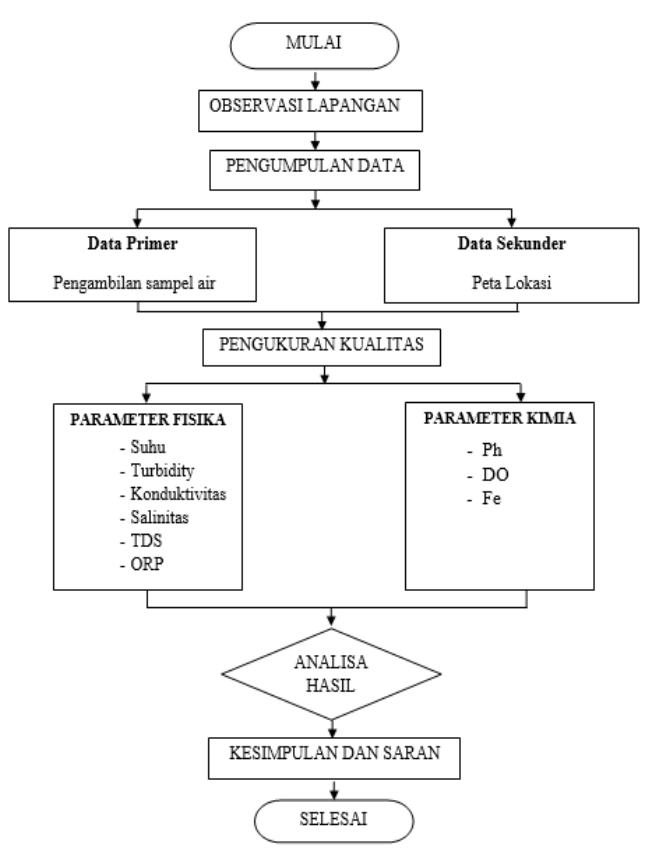

Gambar 1. FlowChart

\subsection{Lokasi dan Waktu Penelitian}

Lokasi penelitian dilakukan di Sungai Klawili Kota Sorong. Sampel air diambil pada 3 titik pantau yaitu titik pantau I (hulu), titik pantau II (tengah), dan titik pantau 3 (hilir) pada Sungai Klawili, dimana daerah hulu (Jl. Madukoro), tengah (Jl. Ataa), hilir (Jl. Malibela). Penelitian ini dilakukan pada bulan April - Agustus Tahun 2018.

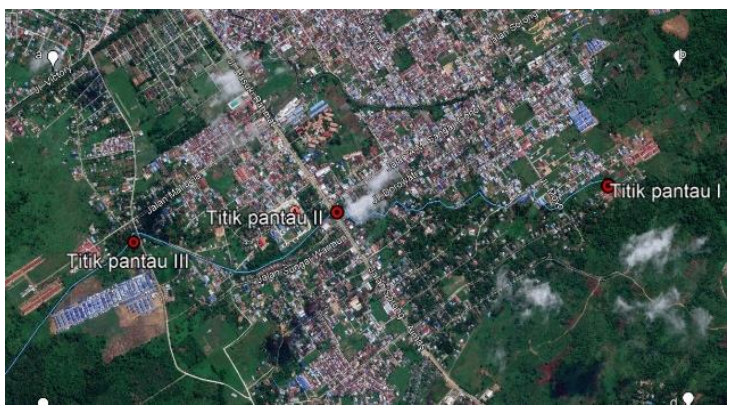

Gambar 2. Lokasi Penelitian

\subsection{Tahapan Penelitian}

Tahapan yang dilakukan dalam penliian ini adalah :

1. Studi literatur

Studi literatur dilakukan dengan mengumpulkan data dan informasi yang dijadikan sebagai referensi dalam sistem pendukung keputusan pengelolaan kualitas air dan pengendalian pencemaran. Referensireferensi tersebut berasal dari buku-buku pegangan maupun publikasi hasil penelitian, artikel, situs internet serta sumber informasi lain yang berkaitan dengan penelitian ini.

2. Pengumpulan data
Terdapat dua tipe data dalam suatu penelitian, yakni data primer dan data sekunder.

- Data primer didapat dengan menggunakan metode survei lapangan dan pengambilan sampel. Pengambilan sampel dilakukan di 3 titik pengamatan. Data yang diambil meliputi parameter fisika dan kimia. Parameter kualitas fisika dan kimia diukur secara langsung (in situ) .

- Data sekunder merupakan data yang didapat bukan dari hasil pengukuran, data ini yang berhubungan dengan kebutuhan penelitian, data sekunder yang digunakan adalah : Peta Sungai Klawili Kota Sorong dan observasi lapangan.

3. Penentuan Parameter Status Mutu Air

Pada penelitian ini terdapat beberapa parameter yang digunakan untuk menentukan status mutu air Sungai Klawili dengan menggunakan metode Indeks Pencemaran. Parameter yang digunakan adalah parameter fisika yaitu TDS dan parameter kimia yaitu $\mathrm{pH}, \mathrm{DO}$, dan Fe.

4. Pembuatan Model

Dalam tahap ini dilakukan pembuatan model untuk menentukan kualitas air menggunakan metodemetode yang terkait yaitu metode Indeks Pencemaran (IP).

5. Analisis Hasil

Pada tahap ini dilakukan analisis dari hasil pembuatan model yang telah dibuat. Mendeskripsikan hasil dari penelitian dilapangan berupa data dan dibandingkan dengan standar kualitas air yang dikeluarkan oleh pemerintah. pada Peraturan Pemerintah No. 82 tahun 2001 Tentang Pengelolaan kualitas Air dan pengendalian Pencemaran Air dan dijelaskan atau ditafsirkan didukung dengan teori-teori.

\subsection{Bahan dan Alat Uji}

1. Bahan yang digunakan dalam penelitian adalah sampel air Sungai Klawili km.12.

2. Alat yang digunakan dalam penelitian ini adalah
a) $\mathrm{pH}$ meter
b) TDS meter
c) Alat ukur kualitas air portable AMT-03R
d) Turbidity meter
e) DO meter AMT-07
f) GPS
g) ORP meter
h) Iron test kit

\section{Hasil Penelitian}

Penelitian kualitas air dilakukan di tiga titik pantau. Penentuan titik pantau sebagai titik pengambilan sampel air sungai menggunakan pusposive sampling method berdasarkan pada kemudahan akses, biaya maupun waktu dalam 
penelitian ini. Dari hasil uji sampel yang di lakukan pada tiga titik terhadap Sungai Klawili didapatkan hasil sebagai berikut :
Tabel 1. Hasil pengukuran parameter fisik dan

\begin{tabular}{|c|c|c|c|c|c|c|c|c|c|c|}
\hline \multirow{3}{*}{ Titik Pantau } & \multirow{3}{*}{ Penelitiar } & \multirow{3}{*}{ Jarak $(\mathbf{m})$} & \multicolumn{5}{|c|}{ Fisika } & \multicolumn{3}{|c|}{ Kimia } \\
\hline & & & $\begin{array}{c}\text { Turbidity } \\
\text { (NTU) } \\
\end{array}$ & $\begin{array}{c}\text { Cond } \\
(\mu \mathrm{s})\end{array}$ & $\begin{array}{c}\begin{array}{c}\text { Salinitas } \\
(\mathrm{mg} / \mathrm{L})\end{array} \\
\end{array}$ & $\begin{array}{c}\begin{array}{c}\text { TDS } \\
(\mathrm{mg} / \mathrm{L})\end{array} \\
\end{array}$ & $\begin{array}{l}\text { ORP } \\
(\mathrm{mV})\end{array}$ & $\mathrm{pH}$ & $\begin{array}{c}\text { DO } \\
(\mathrm{mg} / \mathrm{L})\end{array}$ & $\begin{array}{c}\begin{array}{c}\mathrm{Fe} \\
(\mathrm{mg} / \mathrm{L})\end{array} \\
\end{array}$ \\
\hline & & & \multicolumn{8}{|c|}{ Nilai Parameter } \\
\hline \multirow{6}{*}{1 (HULU) } & 1 & 4150 & 8 & 135 & 67 & 79 & 171 & 5.6 & 4.77 & 0.2 \\
\hline & 2 & 4150 & 9 & 115 & 57 & 72 & 112 & 5.5 & & 0.8 \\
\hline & 3 & 4150 & 12 & 88 & 44 & 66 & 142 & 6.1 & 4.64 & 0.6 \\
\hline & 4 & 4150 & 11 & 107 & 53 & 53 & 130 & 6.2 & 4.33 & 0.6 \\
\hline & 5 & 4150 & 7 & 162 & 81 & 70 & 216 & 6.0 & 3.86 & 0.6 \\
\hline & 6 & 4150 & 9 & 140 & 69 & 51 & 199 & 6.5 & 4.51 & 0.4 \\
\hline \multirow{6}{*}{$\begin{array}{c}2 \\
\text { (TENGAH) }\end{array}$} & 1 & 3460 & 67 & 599 & 298 & 354 & 150 & 6.3 & 1.75 & 1.2 \\
\hline & 2 & 3460 & 27 & 486 & 241 & 283 & 150 & 6.0 & & 3.8 \\
\hline & 3 & 3460 & 23 & 306 & 137 & 201 & 141 & 6.4 & 2.17 & 3.2 \\
\hline & 4 & 3460 & 19 & 214 & 107 & 123 & 146 & 6.3 & 2.64 & 1.2 \\
\hline & 5 & 3460 & 20 & 328 & 163 & 163 & 219 & 6.1 & 2.98 & 3.4 \\
\hline & 6 & 3460 & 20 & 235 & 118 & 108 & 199 & 6.7 & 3.15 & 0.8 \\
\hline \multirow{6}{*}{3 (HILIR) } & 1 & 2250 & 22 & 753 & 404 & 461 & 163 & 6.6 & 3.26 & 1.2 \\
\hline & 2 & 2250 & 20 & 1249 & 636 & 656 & 155 & 5.9 & & 3 \\
\hline & 3 & 2250 & 19 & 479 & 240 & 246 & 119 & 6.7 & 4.43 & 3.5 \\
\hline & 4 & 2250 & 11 & 309 & 153 & 163 & 151 & 6.5 & 3.57 & 2 \\
\hline & 5 & 2250 & 15 & 389 & 194 & 192 & 217 & 6.1 & 3.69 & 3 \\
\hline & 6 & 2250 & 20 & 280 & 140 & 126 & 202 & 6.6 & 3.43 & 3.2 \\
\hline
\end{tabular}

Tabel 2. Hasil Perbandingan Analisa Kualitas Air Sungai Remu Dengan Baku Mutu

\begin{tabular}{|c|c|c|c|c|c|c|c|c|}
\hline \multirow{3}{*}{ Parameter } & \multirow{3}{*}{ Satuan } & \multirow{2}{*}{\multicolumn{3}{|c|}{$\begin{array}{c}\text { Lokasi Sampel } \\
\text { Rata-rata }\end{array}$}} & \multirow{2}{*}{\multicolumn{4}{|c|}{ Baku Mutu (PP No. 82 Tahun 2001) }} \\
\hline & & & & & & & & \\
\hline & & Hulu & Tengah & Hilir & I & II & III & IV \\
\hline \multicolumn{9}{|l|}{ Fisik } \\
\hline Temperatur & ${ }^{\circ} \mathrm{C}$ & 28 & 28 & 29 & Deviasi 3 & Deviasi 3 & Deviasi 3 & Deviasi 5 \\
\hline Turbidity & NTU & 0 & 0 & 0 & - & - & - & - \\
\hline Konduktivitas & $\mu \mathrm{S}$ & 0 & 0 & 0 & - & - & - & - \\
\hline Salinitas & $\mathrm{mg} / \mathrm{l}$ & 0 & 0 & 0 & - & - & - & - \\
\hline TDS & $\mathrm{mg} / \mathrm{l}$ & 0 & 0 & 0 & 1000 & 1000 & 1000 & 2000 \\
\hline ORP & $\mathrm{mV}$ & 0 & 0 & 0 & - & - & - & - \\
\hline \multicolumn{9}{|l|}{ Kimia } \\
\hline $\mathrm{pH}$ & & 0.0 & 0 & 0.0 & $6 \mathrm{sd} 9$ & $6 \mathrm{sd} 9$ & $6 \mathrm{sd} 9$ & 5 sd 9 \\
\hline DO & $\mathrm{mg} / \mathrm{l}$ & 0.00 & 0.00 & 0.00 & 6 & 4 & 3 & 0 \\
\hline $\mathrm{Fe}$ & $\mathrm{mg} / \mathrm{l}$ & 0.0 & 0.0 & 0.0 & 0.3 & - & - & - \\
\hline
\end{tabular}

\section{Pembahasan}

\subsection{Penentuan Status Mutu Air Menggunakan Metode Indeks Pencemaran.}

Status mutu air adalah tingkat kondisi mutu air yang menunjukkan kondisi cemar atau kondisi baik pada suatu sumber air dalam waktu tertentu dengan membandingkan dengan baku mutu air yang ditetapkan. Sungai dikatakan tercemar apabila tidak dapat digunakan sesuai dengan peruntukannya secara normal. Dalam penelitian ini parameter yang digunakan dalam menganalisis status mutu air adalah TDS, pH, DO dan Fe. Sedangkan parameter Kekeruhan, Konduktivitas, Salinitas dan ORP sebagai parameter pendukung.

Berdasarkan hasil analisa perhitungan dengan menggunakan metode Indeks Pencemaran maka diketahui status mutu air Sungai Klawili dari hulu hingga ke hilir telah tercemar dan masuk dalam kategori cemar ringan untuk seluruh baku mutu air kelas 1 dimana peruntukannya dapat digunakan untuk air baku air minum berdasarkan Peraturan Pemerintah Nomor 82 Tahun 2001. Sedangkan untuk status mutu Sungai Klawili masuk dalam kategori kondisi baik/memenuhi untuk baku mutu air kelas II-IV dimana peruntukannya dapat digunakan untuk prasarana/sarana rekreasi air, pembudidayaan ikan air tawar, peternakan, air untuk mengairi pertanaman, dan atau peruntukan lain yang mempersyaratkan mutu air yang sama dengan kegunaan tersebut.

Tabel 3. Hasil perhitungan menggunakan metode indeks pencemaran

\begin{tabular}{|c|c|c|c|c|c|c|c|c|c|}
\hline \multirow{2}{*}{$\begin{array}{c}\text { TITIK } \\
\text { PANTAU }\end{array}$} & \multirow{2}{*}{ URAIAN } & \multicolumn{6}{|c|}{ STATUS MUTU AIR SUNGAI KLAWILI } & \multirow{2}{*}{ Rata-rate } & \multirow{2}{*}{ KESIMPULAN } \\
\hline & & I & II & III & IV & $\mathbf{v}$ & VI & & \\
\hline \multirow{4}{*}{1 (HULU) } & Kelas I & 0.973 & 2.364 & 1.885 & 1.881 & 1.891 & 1.250 & 1.707 & Cemar Ringan \\
\hline & Kelas II & 0.915 & 0.983 & 0.690 & 0.642 & 0.756 & 0.515 & 0.750 & Memenuhi \\
\hline & Kelas III & 0.915 & 0.983 & 0.690 & 0.642 & 0.756 & 0.515 & 0.750 & Memenuhi \\
\hline & Kelas IV & 0.914 & 0.981 & 0.688 & 0.640 & 0.754 & 0.196 & 0.695 & Memenuhi \\
\hline \multirow{4}{*}{$\begin{array}{c}2 \\
\text { (TENGAH) }\end{array}$} & Kelas I & 2.993 & 4.817 & 4.532 & 2.981 & 4.631 & 2.348 & 3.717 & Cemar Ringan \\
\hline & Kelas II & 0.618 & 0.768 & 0.546 & 0.603 & 0.682 & 0.430 & 0.608 & Memenuhi \\
\hline & Kelas III & 0.618 & 0.768 & 0.546 & 0.603 & 0.682 & 0.430 & 0.608 & Memenuhi \\
\hline & Kelas IV & 0.606 & 0.760 & 0.539 & 0.599 & 0.678 & 0.407 & 0.598 & Memenuhi \\
\hline \multirow{4}{*}{3 (HILIR) } & Kelas I & 2.984 & 4.465 & 4.661 & 3.780 & 4.433 & 2.350 & 3.779 & Cemar Ringan \\
\hline & Kelas II & 0.464 & 0.809 & 0.428 & 0.506 & 0.682 & 0.477 & 0.561 & Memenuhi \\
\hline & Kelas III & 0.464 & 0.809 & 0.428 & 0.506 & 0.682 & 0.477 & 0.561 & Memenuhi \\
\hline & Kelas IV & 0.446 & 0.787 & 0.419 & 0.501 & 0.677 & 0.161 & 0.498 & Memenuhi \\
\hline
\end{tabular}




\subsection{Pengaruh Tata Ruang Bantaran Sungai Klawili Terhadap Status Mutu Air}

Dari hasil observasi yang dilakukan ditemui banyak buangan limbah rumah tangga dan buangan sampah dari masyarakat yang bermukim disekitar bantaran sungai, hal ini berpengaruh bagi kualitas air sungai, dalam tata ruang bantaran sungai yang mengacu pada Peraturan Pemerintah Nomor 82 Tahun 2001 untuk Sungai Klawili kurang dari 15 meter pada anak-anak sungai di kawasan pemukiman. Dari hasil survei penyebab terjadinya pencemaran dan penurunan kualitas air Sungai Klawili tersaji dalam gambar berikut :

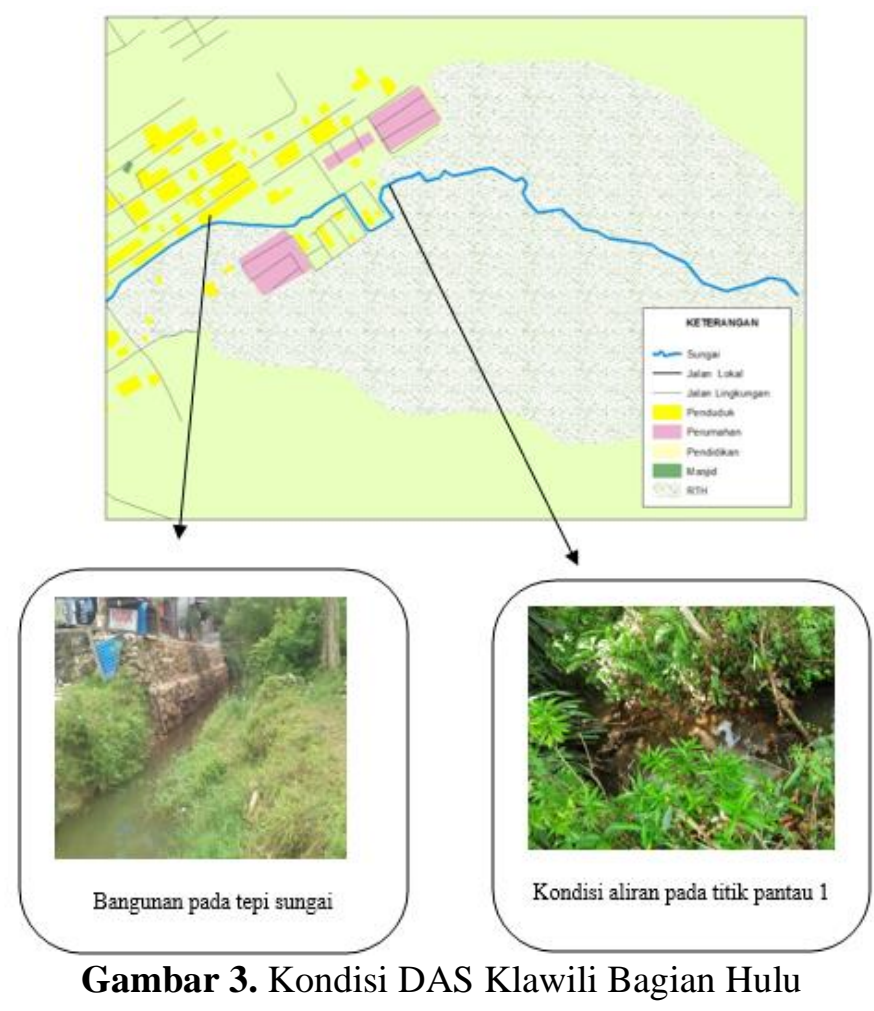

Pada lokasi pengambilan sampel di titik pantau 1 (hulu) dimana kondisi tata ruang pada bantaran sungai sudah terjadi pencemaran, dikarenakan pada daerah titik pantau 1 didominasi oleh RTH (Ruang Terbuka Hijau) yang memungkinkan adanya limbah organik dari tumbuhan yang telah membusuk, serta adanya perumahan penduduk yang terpisahpisah yang limbahnya langsung dialirkan ke sungai sehingga menyebabkan air sungai tercemar. 


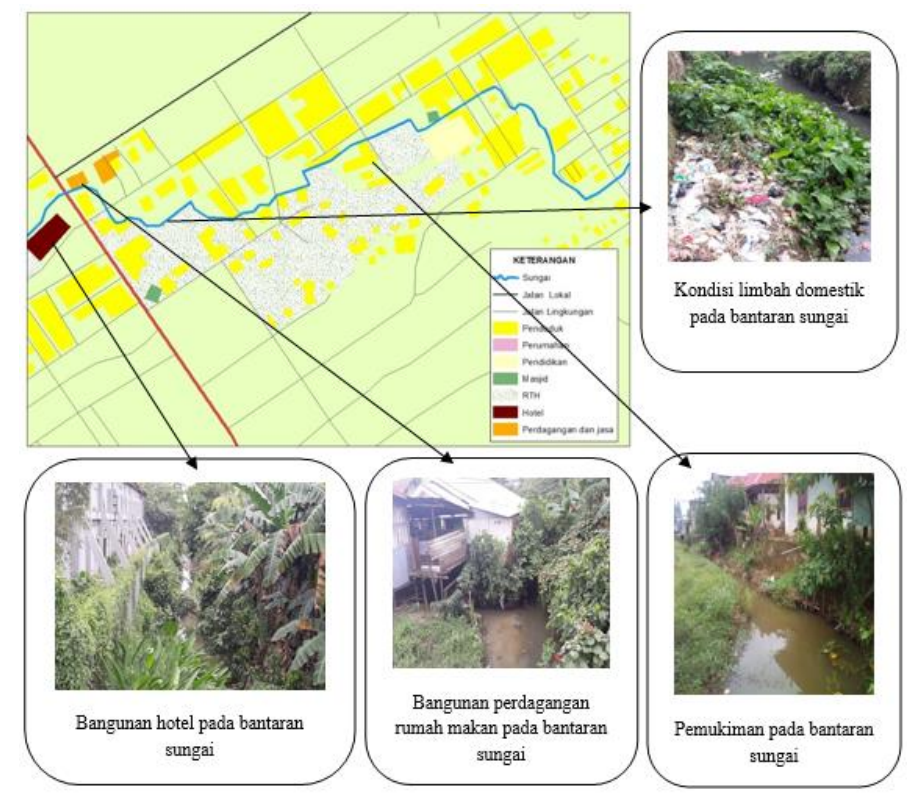

Gambar 4. Kondisi DAS Klawili Bagian Tengah

Pada lokasi pengambilan sampel di titik pantau II (tengah) status mutu air Sungai Klawili masuk dalam kategori cemar ringan. Hal ini disebabkan karena konsentrasi DO lebih rendah dan konsentrasi $\mathrm{Fe}$ tinggi. Apabila dilihat dari kondisi tata ruang DAS Klawili, pada bantaran Sungai Klawili di sekitaran lokasi pengambilan sampel pada titik II (tengah) didominasi oleh perumahan penduduk dan juga terdapat bangunan perdagangan rumah makan pada bantaran sungai yang limbah buangannya langsung dialirkan ke sungai dan juga terdapat banyak tumpukan sampah.

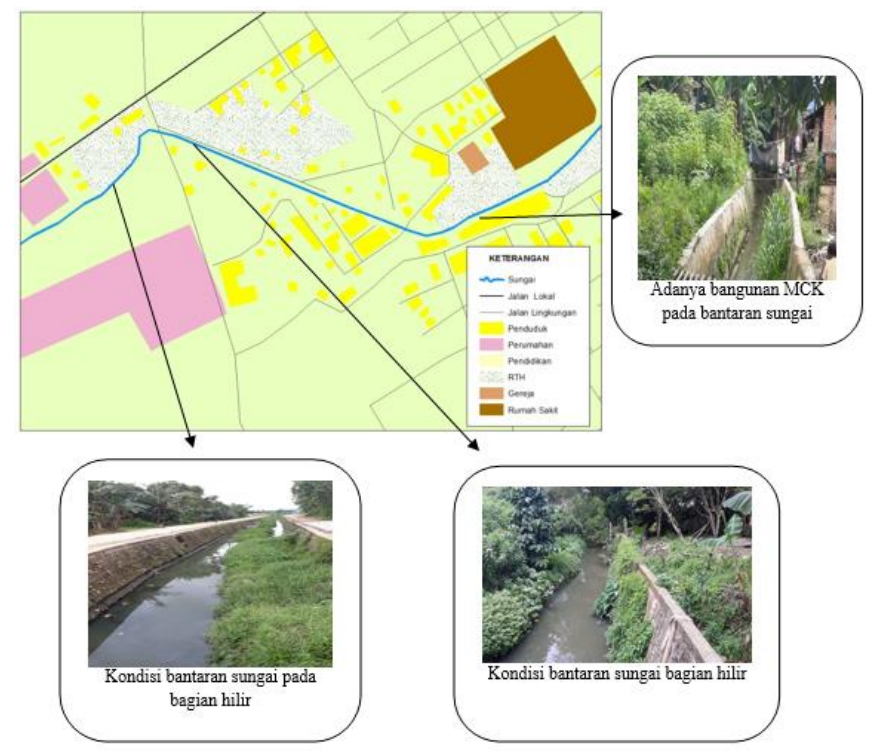

Gambar 5. Kondisi DAS Klawili Bagian Hilir

Pada lokasi pengambilan sampel di titik pantau III (Hilir) status mutu air Sungai Klawili masuk dalam kategori cemar ringan. Hal ini disebabkan karena meningkatnya polutan. Apabila dilihat dari kondisi tata ruang DAS Klawili, pada bantaran Sungai Klawili disekitaran lokasi pengambilan sampel pada titik pantau 3 (Hilir) didominasi oleh perumahan penduduk yang terpisah-pisah yang mana buangan limbah domestik (rumah tangga) langsung dialirkan ke sungai sehinnga menyebabkan air sungai tercemar.

\subsection{Rekomendasi Pencemaran Air}

Pengendalian 
Dari hasil penelitian ini disimpulkan bahwa status mutu air pada Sungai Klawili masuk dalam kategori cemar ringan. Oleh karena itu diperlukan beberapa upaya pengendalian untuk mengurangi pencemaran Sungai Klawili. Pengendalian pencemaran untuk Sungai Klawili sebagai berikut: (a) Perlu dilakukan sosialisasi kepada masyarakat agar meningkatkan kesadaran masyarakat untuk tidak mengalirkan limbah domestik (rumah tangga) langsung ke sungai. (b) Diperlukan pembuatan septictank karena adanya limbah cair domestik (rumah tangga) yang langsung dialirkan ke sungai serta pembuatan MCK yang jauh dari bantaran sungai agar menghindari pembuangan langsung ke sungai. (c) Perlu adanya pembuatan bak sampah pada beberapa tempat disepanjang Sungai Klawili dan sirkulasi pengambilan sampah yang berkala karena banyaknya masyarakat yang membuang sampah langsung ke sungai sehingga tidak terjadi penumpukan sampah pada bak-bak sampah yang telah dibuat,. Dimana Dinas Lingkungan Hidup dan Dinas Kebersihan Pengelolaan sampah diatur dalam UndangUndang Nomor 18 Tahun 2008.

\section{Kesimpulan}

Berdasarkan tujuan penelitian dan data yang telah dianalisa, maka diperoleh kesimpulan sebagai berikut: (1) Kualitas air Sungai Klawili menggunakan metode Indeks Pencemaran dengan uji parameter (TDS, pH, DO, dan Fe) menunjukkan penurunan kualitas air. Pada bagian hulu menunjukkan status cemar ringan untuk baku mutu air kelas 1 karena rendahnya nilai kadar $\mathrm{pH}$ dengan niali 5,5, dan kondisi baik/memenuhi sesuai peruntukannya pada baku mutu kelas II-IV, bagian tengah menunjukkan status cemar ringan untuk baku mutu kelas I karena rendahnya kadar DO dengan nilai $1,75 \mathrm{mg} / \mathrm{l}$ serta meningkatnya konsentrasi $\mathrm{Fe}$ dengan nilai $3,8 \mathrm{mg} / \mathrm{l}$, dan kondisi baik/memenuhi sesuai peruntukukannya pada kelas II-IV. Sedangkan pada bagian hilir menunjukkan status cemar ringan untuk baku mutu kelas I karena tingginya konsentrasi $\mathrm{Fe}$ dengan nilai $3,5 \mathrm{mg} / \mathrm{l}$ dan rendahnya $\mathrm{pH}$ dengan nilai 5,9 serta kondisi baik/memenuhi sesuai peruntukannya untuk kelas II-IV. (2) Kondisi Tata Ruang bantaran Klawili sangat berpengaruh terhadap kualitas air sehingga menjadikan perubahan konsentrasi parameter, selain itu juga yang menjadi faktor penyebabnya berkaitan dengan aktivitas manusia di bantaran sungai yang sebagian besar masyarakat bantaran sungai masih membuang sampah langsung ke sungai. Kemudian limbah domestik maupun industri yang juga dibuang langsung kesungai. (3) Untuk rekomendasi pengendalian pencemaran air Sungai Klawili yaitu perlu adanya pembuatan septictank dan pembuatan bak sampah dibeberapa tempat di sepanjang Sungai Klawili dan sirkulasi pengambilan sampah yang berkala sehingga tidak terjadi penumpukan sampah pada bak-bak sampah yang telah dibuat.

\section{Referensi}

Effendi, H. (2003) : Telaah Kualitas Air, Kanisius, Yogyakarta.

Peraturan Pemerintah Nomor 82 (2001), Tentang Pengelolaan Kualitas Air Dan Pengendalian Pencemaran Air.

Pristianto, H. \& Rusdi Achmad (2017) : Evaluasi Pengelolaan DAS dan Wilayah Pesisir di Kota Sorong. 
